\title{
Labour Supply and the Extensive Margin
}

\author{
By Richard Blundell, Antoine Bozio and Guy Laroque*
}

Forty years ago the Europeans (here French and British) used to work more than the Americans. They now work less. The aim of this paper is to provide a coherent picture of these changes. To do so we split the overall level of work activity into the number of individuals in work and the intensity of work supplied by those in work. This reflects the distinction between whether to work and how much to work at the individual level and is referred to, respectively, as the extensive and intensive margin of labour supply.

The difference between the extensive and intensive margins has been highlighted in recent research attempting to resolve differences between micro and macro responses of labour supply to tax reform. For example, Rogerson and Wallenius (2009), following the work of Prescott (2004), argue that the responsiveness of the extensive margin of labour supply to taxation plays a major role in explaining aggregate differences in total hours worked across countries. They show that an economy with fixed technology costs for firms and an inverted Ushape life-cycle productivity for workers can produce large aggregate extensive labour supply responses driven by movements in employment at either end of the working life. This, they argue, can reconcile the small micro-based elasticities of hours worked with the large responses required if taxes and social security are to explain crosscountry differences in total hours of work.

The distinction between the extensive and intensive margin has long been recognised in microeconometric studies of labour supply, especially for women with children (James Heckman

* Blundell: University College London (UCL) and Institute for Fiscal Studies (IFS), 7 Ridgmount Street WC1E 7AE London United Kingdom, r.blundell@ucl.ac.uk. Bozio: UCL and IFS, antoine_b@ifs.org.uk. Laroque: UCL, IFS and CREST, g.laroque@ucl.ac.uk. We thank Steve Davis and participants at the AEA session for comments, and the Data archive UK, INSEE and IUPMS for data access.
1974, Richard Blundell and Thomas MaCurdy 1999), and in studies of older workers (Jonathan Gruber and David Wise 1999). The relative size of labour supply responses at the intensive and extensive margin has also been a key parameter in the public economics literature on earnings tax design (Emmanuel Saez 2002, Guy Laroque 2005, Mike Brewer, Emmanuel Saez and Andrew Shephard 2010).

But what do we know about the importance of these margins for different types of workers? How well does the extensive margin explain changes in aggregate hours? In this paper we provide a decomposition of the evolution of aggregate hours of work into changes at the extensive and intensive margin. More details are available in the companion paper (Richard Blundell, Antoine Bozio and Guy Laroque 2011), where we also develop a life-cycle model that delivers an aggregate total hours elasticity in terms of the distribution of intensive and extensive elasticities at the micro level.

We examine three key countries, the US, the UK and France, over the forty year period up to 2008. These three countries stand respectively at the top, middle and bottom of Prescott's table of labour supply. The UK provides an interesting comparison with the polar cases of France and the US. They are also countries where we can access nationally representative detailed microdata over a long period of time (see supplementary material) so as to examine the relationship between the extensive and intensive margin across different individual types.

Figure 1.A highlights the key piece of evidence used to motivate our analysis. It charts the evolution of the average annual hours of work per individuals aged 16 to 74 from 1968 to 2008 . The pattern of total hours per individual shows evidence of a three way split after 1980 in the evolution of total hours across the three countries, hiding different evolutions of employment and hours per worker.

Overall employment rates in the UK and the 


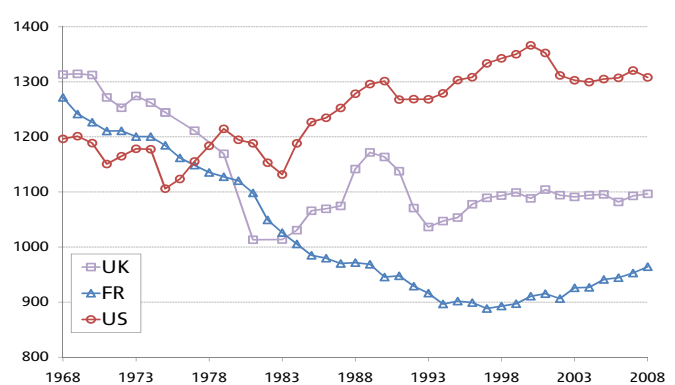

A. MEAN ANNUAL HOURS PER INDIVIDUAL

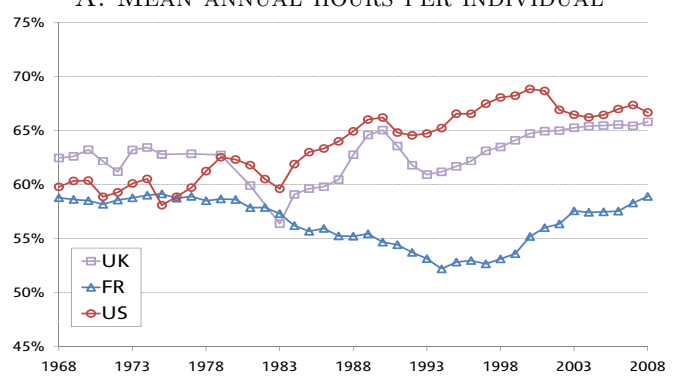

B. Employment Rate (Per population)

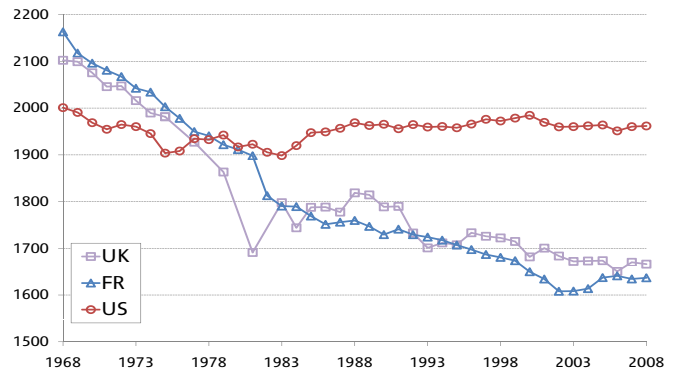

C. MeAn AnNual hours Per WORKER

Figure 1. Measures of market wOrk

Sources: Enquête Emploi, Labour Force Survey, Current Population Survey.

US have moved somewhat in line with each other showing an increase over this period. Employment rates in France have progressed very differently. Figure 1.B shows a strong decline in employment in France until the mid-1990s with recovery thereafter but leaving a large difference in current employment rates.

Changes in hours per worker tell a different story. Figure 1.C shows the UK and France following each other with strong declines over this period stabilizing somewhat in the 2000s. In contrast, the US has retained a stable pattern of hours per worker over the entire period apart from a dip in the late 1970s and early 1980s.

\section{Bounding Changes at the Extensive and Intensive Margins}

Our central interest is how the overall average hours worked per person in any year $t, H_{t}$, varies over time and across countries, in particular along the intensive and extensive margins. Of course, average hours worked differs across different people, by age and gender for instance. Suppose there are $j=1, \ldots, J$ such broad categories. $H_{t}$ is computed as the sum of average hours per person for each category, $H_{j t}$, weighted by their population shares $q_{j t}$. We decompose $H_{j t}$ as the product of hours per worker $h_{j t}$ and participation in the labour market $p_{j_{t}}$.

When we observe a change in yearly hours worked per person, $H_{t}-H_{t-1}$, we would like to be able to know how much of the change is due to the intensive or extensive margins. To achieve this we propose a statistical decomposition: First we measure the change due to the behavior of category $j$, holding the population structure constant as in date $t-1$, as in a Laspeyres index

$$
\Delta_{j t}=q_{j, t-1}\left[H_{j t}-H_{j, t-1}\right]
$$

The total change across all $J$ categories of workers is simply

$$
\Delta_{t}=\sum_{j=1}^{J} \Delta_{j t}
$$

and we have, by construction

$$
H_{t}-H_{t-1}=S_{t}+\Delta_{t} .
$$

where $S_{t}$ is a structural effect due to the change in the composition of the population given by $\sum_{j=1}^{J} H_{j t}\left[q_{j t}-q_{j, t-1}\right]$.

There is no obvious way to decompose the change in total hours experienced by category $j$ into the sum of an extensive $E_{j}$ and an intensive $I_{j}$ components. It is however natural to suppose that any plausible measure $I_{j}$ of the intensive margin would have the same sign as the difference of the hours worked per worker at date $t-1$ and $t: \Delta h_{j}=h_{j t}-h_{j, t-1}$. Assuming linearity, 
we can then express the change $\Delta_{j}$ as the sum of an intensive component $I_{j}=p_{I j} \Delta h_{j}$ and an extensive component $E_{j}=h_{E j} \Delta p_{j}$. Supposing the fraction $p_{I j}$ is in the interval $\left[p_{j, t-1}, p_{j t}\right]$, we get the intensive bounds

$$
I_{j} \in\left[p_{j, t-1}\left(h_{j t}-h_{j, t-1}\right), p_{j, t}\left(h_{j t}-h_{j, t-1}\right)\right] .
$$

From the identity $\Delta_{j t}=I_{j}+E_{j}$, the extensive bounds are given by

$$
E_{j} \in\left[h_{j, t-1}\left(p_{j t}-p_{j, t-1}\right), h_{j, t}\left(p_{j t}-p_{j, t-1}\right)\right] .
$$

At the limits, the change in total hours for any category of workers satisfies two polar exact statistical decompositions:

$$
\begin{aligned}
& \Delta_{j t}=q_{j, t-1}\left\{\left[h_{j t}-h_{j t-1}\right] p_{j t}+\left[p_{j t}-p_{j t-1}\right] h_{j t-1}\right\} \\
& \Delta_{j t}=q_{j, t-1}\left\{\left[h_{j t}-h_{j t-1}\right] p_{j t-1}+\left[p_{j t}-p_{j t-1}\right] h_{j t}\right\} .
\end{aligned}
$$

The first term on the rhs of both expressions is the intensive margin, weighted in the top formula (4) with the final participation rate (as in a Paasche index) and in the bottom formula (5) with the initial participation rate (as in a Laspeyres index). The second term is the extensive margin (Laspeyres in (4), Paasche in (5)).

\section{Decomposing Total Hours Worked}

In this section we turn to the empirical analysis and first examine the evolution of $h_{j t}$ and $p_{j t}$ for different age and gender groups. We then use (4) and (5) to provide bounds on the importance of intensive and extensive margins in the evolution of hours worked across these various groups. We focus on the comparison between 1977 and 2007, a period for which we are more certain of the reliability of our data.

The lines $\Delta$ of Table 1 show the contributions of the categories and the effect of demographic structure, according to equations (1), (2) and (3). Two clear features emerge: First, for nearly all the categories the US and France are at the extremes with the UK in between. The contribution to the aggregate of the hours worked by the young and prime age men is negative in all countries. The decline in absolute value is smallest in the US, and increases when one goes from the US to the UK, and then to France. Second, the increased participation of women works against the general trend. This is particularly obvious for women aged 30-54, who all work more in 2007 than in 1977 , but also for the old and young.

Using the statistical bounds framework developed in the previous section we can go further and, in Table 2, we examine what part of any overall change in hours is attributable to changes at the extensive or intensive margin for any particular subgroup of the population. The row [I$\mathrm{L}, \mathrm{I}-\mathrm{P}]$ shows the bounds on the intensive margin, ( $L$ standing for Laspeyres, $P$ for Paasche), while the row $[\mathrm{E}-\mathrm{L}, \mathrm{E}-\mathrm{P}]$ shows the bounds on the extensive margin.

As a concrete example, examine the first entry in the top left of Table 2, French men aged 16-29. The impact on total hours for this group is -82 . The I-L index of -37 tells us that the intensive margin does a good bit but not the majority of the work in explaining total hours changes for this group. The E-L estimate of -54 confirms the relative importance of the extensive margin for this group.

Turning first to prime-age workers, the steep decline at the intensive margin for prime aged men in France and the UK relative to the US is striking. For this group the bounds are quite narrow and leave little room for ambiguity. These changes represent an enormous shift in the relative position of these countries. Increases in effective marginal tax rates and/or the regulation of working hours could explain these patterns. In terms of regulation Britain has seen fewer changes than France and yet has experienced similar changes.

Income effects could be part of the explanation. There are two potential sources for these. First, as the economy grows individuals may prefer to take some of the gains in income in terms of increased leisure, cutting back their hours of work. However, given overall growth has been somewhat similar across all three countries, it would have to be that Europeans take more leisure in response to rises in income. A second source of income effect for prime age men is the increased participation by women. This is often termed the added-worker effect. Prime-aged women have certainly seen a strong increase in participation. Indeed, the bounds on the exten- 
TABle 1-The Evolution of hours of WORK Between 1977 AND 2007 By Gender ANd Age Groups

\begin{tabular}{cccccccccc}
\hline & Year & \multicolumn{2}{c}{ Youth (16-29) } & \multicolumn{2}{c}{ Prime aged (30-54) } & \multicolumn{2}{c}{ Old (55-74) } & Residual & All \\
& & Men & Women & Men & Women & Men & Women & & $(16-74)$ \\
\hline \hline FR & 1977 & 1402 & 871 & 2010 & 951 & 827 & 367 & & 1148 \\
& 2007 & 858 & 627 & 1639 & 1116 & 508 & 344 & & 953 \\
& $\Delta$ & -82 & -38 & -82 & 36 & -36 & -3 & 10 & -195 \\
\hline UK & 1977 & 1707 & 938 & 2117 & 873 & 1107 & 323 & & 1212 \\
& 2007 & 1219 & 876 & 1786 & 1055 & 790 & 385 & & 1094 \\
& $\Delta$ & -71 & -9 & -70 & 39 & -42 & 10 & 25 & -118 \\
\hline US & 1977 & 1344 & 835 & 2018 & 947 & 1025 & 447 & & 1156 \\
& 2007 & 1236 & 956 & 1922 & 1373 & 1084 & 754 & & 1321 \\
& $\Delta$ & -19 & 22 & -19 & 90 & 6 & 38 & 46 & 165 \\
\hline \multicolumn{7}{c}{ Note: $\Delta$ are computed following equation $(1)}$. & &
\end{tabular}

TABle 2-The EXtensive AND Intensive Margins BETWEen 1977 And 2007

\begin{tabular}{ccccccccc}
\hline & Year & \multicolumn{2}{c}{ Youth $(16-29)$} & \multicolumn{2}{c}{ Prime aged (30-54) } & \multicolumn{2}{c}{ Old (55-74) } & All \\
& & Men & Women & Men & Women & Men & Women & $(16-74)$ \\
\hline \hline FR & $\Delta$ & -82 & -38 & -82 & 36 & -36 & -3 & -195 \\
& {$[$ I-L, I-P] } & {$[-37,-28]$} & {$[-23,-19]$} & {$[-59,-56]$} & {$[-35,-49]$} & {$[-11,-8]$} & {$[-9,-10]$} & {$[-185,-183]$} \\
& {$[$ E-L, E-P] } & {$[-54,-45]$} & {$[-19,-16]$} & {$[-27,-23]$} & {$[85,71]$} & {$[-28,-25]$} & {$[7,6]$} & {$[-12,-10]$} \\
UK & $\Delta$ & -71 & -9 & -70 & 39 & -42 & 10 & -118 \\
& {$[$ I-L, I-P $]$} & {$[-42,-36]$} & {$[-23,-26]$} & {$[-48,-45]$} & {$[-2,-3]$} & {$[-22,-19]$} & {$[-6,-8]$} & {$[-161,-167]$} \\
& {$[$ E-L, E-P] } & {$[-35,-29]$} & {$[17,14]$} & {$[-25,-22]$} & {$[41,41]$} & {$[-23,-20]$} & {$[17,15]$} & {$[50,43]$} \\
US & $\Delta$ & -19 & 22 & -19 & 90 & 6 & 38 & 165 \\
& {$[$ I-L, I-P] } & {$[-6,-6]$} & {$[1,1]$} & {$[-5,-5]$} & {$[14,19]$} & {$[3,3]$} & {$[3,5]$} & {$[15,17]$} \\
& {$[$ E-L, E-P $]$} & {$[-13,-13]$} & {$[21,21]$} & {$[-14,-14]$} & {$[72,77]$} & {$[3,3]$} & {$[33,35]$} & {$[148,150]$} \\
\hline
\end{tabular}

NoTE: I-P designs the Paasche measure of the intensive margin, I-L the Laspeyre measure, respectively E-P and E-L for the extensive margin, as described by equations (4) and (5).

sive margin changes in Table 2 for women aged 30-54 are the largest positive change to be found in any country-age cell and at any margin. But the largest overall increase, especially when the intensive margin is taken into account, is for US women. Yet the change in hours is the least for US men. Again responses would have to be different in Europe.

Table 2 tells us that the extensive margin for prime-age men in Britain and in France also falls more than in the US, although there are declines in the US too. Increases in relative employment costs or out of work benefits in France and Britain could explain such changes. Income effects may also play a role at the extensive margin as individuals cut back on their overall life-cycle labour supply. However, this seems more likely at either end of the life-cycle.

As we have noted, for prime age women it is the increase at the extensive margin that is so extraordinary, especially in the US and in France where the bounds in Table 2 suggest a very similar change and one that is nearly twice the size of that experienced in the UK. Intensive margins provide somewhat of a puzzle here, falling back strongly in France, staying put in the UK while growing in the US.

For older men and women there is a large decrease in hours per worker in France, similar in the UK, contrasting with an increase in the US. There are falls at the extensive and intensive margins for UK men but increases at the extensive margin for UK women. This surely is linked to the strong increase in women's participation. This phenomena is replicated to some extent across all countries and offsets the stronger incentives to retire earlier in the UK and in France. The contrast with the US is stark, where at all margins and for both genders the bounds point to positive changes for older workers. 
The changes among the young are sizable and predominantly negative. In France and the UK there are large falls for young men at both the extensive and intensive margin.

\section{Conclusions}

In this paper we have proposed a systematic way of examining the importance of the extensive and the intensive margins of labour supply in explaining the overall movements in total hours of work over time. We have shown how informative bounds can be developed on each of these margins. We have applied this analysis to the evolution of hours of work in the US, the UK and France. We have shown that both the extensive and intensive margins matter in explaining changes in total hours.

An objective of this research is to link up the changes at the extensive and intensive margins to movements in the distribution of taxes, relative wages, demographics and other incomes. This will allow us to draw implications for the the aggregate hours elasticity. Davis and Henrekson (2004) note the importance of household production in interpreting these effects. In Blundell et al. (2011), we develop a life-cycle aggregation framework and apply it to the UK using a consistent series on marginal taxes, incomes, hours of work, wages and consumption for a representative sample of households. We focus on individuals aged 30 to 54 . Following Richard Blundell, Alan Duncan and Costas Meghir (1998), we use the large changes in relative growth of after tax wages and other incomes across different education, age and gender groups over the years 1978, 1987, 1997 and 2007, to identify Marshallian and Hicksian elasticities. Frisch elasticities can also estimated using consumption data.

In line with previous empirical studies we find that elasticities for women at both margins are larger than those for men. But we also note that the key determinant of these differences across gender is the age composition of children in the family. For this subpopulation, the median Marshallian extensive elasticity for women is .34, for men is .25, and the distribution has a large spread. The corresponding intensive elasticity ranges between .09 and .23. Using the empirical distribution of the wages and estimated unob- served heterogeneity, we find the aggregate total hours elasticity lies in the range .3 to .44 .

\section{REFERENCES}

Blundell, Richard, Alan Duncan, and Costas Meghir. 1998. "Estimating Labor Supply Responses Using Tax Reforms." Econometrica, 66(4): 827-861.

Blundell, Richard, and Thomas MaCurdy. 1999. "Labor Supply: A Review of Alternative Approaches." In Handbook of Labor Economics. Vol. 3, , ed. Orley Ashenfelter and David Card, 1559-1695. North Holland.

Blundell, Richard, Antoine Bozio, and Guy Laroque. 2011. "Extensive and Intensive Margins of Labour Supply: Working Hours in the US, UK and France." IFS Working paper, , (W11/01).

Brewer, Mike, Emmanuel Saez, and Andrew Shephard. 2010. "Means-testing and Tax Rates on Earnings." Dimensions of Tax Design, , ed. James Mirrlees, 90-173. Oxford University Press.

Davis, Steven, and Magnus Henrekson. 2004. "Tax Effects on Work Activity, Industry Mix and Shadow Economy Size." NBER Working Paper, , (10509).

Gruber, Jonathan, and David Wise. 1999. Social Security and Retirement around the World. NBER/The University of Chicago Press.

Heckman, James. 1974. "Shadow Prices, Market Wages, and Labor Supply." Econometrica, 42(4): 679-694.

Laroque, Guy. 2005. "Income Maintenance and Labor Force Participation." Econometrica, 73(2): 341-376.

Prescott, Edward. 2004. "Why Do Americans Work So Much More than Europeans?" Federal Reserve Bank of Minneapolis Quarterly Review, 28(1): 2-13.

Rogerson, Richard, and Johanna Wallenius. 2009. "Micro and Macro Elasticities in a Life Cycle Model With Taxes." Journal of Economic Theory, 144(6): 2277-2292.

Saez, Emmanuel. 2002. "Optimal Income Transfer Programs : Intensive Versus Extensive Labor Supply Responses." Quarterly Journal of Economics, 117(3): 1039-1073. 